\title{
Determination of Five Pyrethroid Pesticides Residue in Liquid Milk by Gas Chromatography Using Multi-walled Carbon Nanotubes as Dispersion Solid Phase Extraction Sorbent
}

\author{
Y. L. Gao ${ }^{1,2,3}$ and P. Sun ${ }^{1,3^{*}}$ \\ ${ }^{1}$ Testing Centre, Heilongjiang Bayi Agricultural University, Daqing, 163319, P.R. China \\ ${ }^{2}$ Mudanjiang Food and Bio·Technology Innovation Institute, Heilongjiang Bayi Agricultural University, \\ Mudanjiang, 157000, P.R. China \\ ${ }^{3}$ Test Center of Quality Supervision and Inspection of Processed Agricultural Products in Department of Agriculture, \\ Daqing, 163319, P.R. China
}

Received: 13 January 2017; accepted: 13 January 2017

\begin{abstract}
A novel multi-walled carbon nanotubes (MWCNTs) dispersive solid phase extraction (d-SPE) method which combined with gas chromatography (GC) coupled with electron capture detector (ECD) was developed for the determination of five pyrethroid pesticides in liquid milk for the first time. The effect of d-SPE conditions on the kinds of sorbent, MWCNTs and magnesium sulfate anhydro mass ratio, and extraction condition were researched, and then, the suitable method was found. Under the optimal conditions, the linear range was from 20 to $500 \mu \mathrm{g} \mathrm{kg}^{-1}$. The recoveries were from $81.8 \%$ to $112.1 \%$, with the corresponding relative standard deviations (RSDs) less than $6 \%$, correlation coefficients from 0.9978 to 0.9990 , and limits of detection and quantification from 2.62 to $4.86 \mu \mathrm{g} \mathrm{kg}^{-1}$ and 8.73 to $16.2 \mathrm{\mu g} \mathrm{kg}^{-1}$. The proposed method is simple, fast, safe, and has high recovery and sensitivity applicable to analyze pyrethroid pesticides in liquid milk sample.
\end{abstract}

Keywords: MWCNTs, d-SPE, GC, pyrethroid pesticides, liquid milk

\section{Introduction}

Pyrethroid pesticides, characterized by remarkable biodegradability and low toxicity, are of the third generation after organochlorine and organophosphorus insecticides; used far and wide in pest control of crops such as vegetables and fruits, they have become the world's most widely used insecticides. Improper or excessive use of them will easily leave residues in crops, which directly cause enormous harm to human health through the food chain [1]. At present, the main methods for detecting residues of pyrethroid pesticides include gas chromatography (GC) [2-4], GC-mass spectrometry (MS) [5-7], high-performance liquid chromatography (HPLC) [8, 9], and liquid chromatography (LC)-MS [10-12]. LC-MS and GC-MS, albeit for qualitative and quantitative purposes, are difficult to equip and use on a large scale due to costly instruments and demanding tasks of operation; therefore, GC, known for its high sensitivity and wide scope of use, has proved to be a powerful technique of analysis in insecticide-residue research.

Codex Alimentarius Commission (CAC), Positive List System of Japan, and the European Union (EU) have made stipulations concerning the maximum residue limits (MRLs) of the pyrethroid pesticides residues in milk [13, 14]; it could be limited within 20 to $40 \mu \mathrm{g} \mathrm{kg}^{-1}$, but there is no definite requirement for the maximum residue of the pyrethroid pesticides in liquid milk in China. Therefore, establishment of methods for detection and analysis of pyrethroid pesticides residues in liquid milk is very urgent. Sample pretreatment is a key technology in the process of analysis, especially for samples of liquid milk with complex composition and low amount of residue. Dispersive solid phase extraction (d-SPE) is based on the addition of the sorbent material into the extract to remove the matrix con-

* Author for correspondence: byndsunpeng@sina.com comitants. d-SPE is another novel sample preparation technique which offers unique advantages such as simplicity, low solvent use, safety, and automation. Recently, this method has been successfully used to clean up liquid samples or the extracts of various samples [15-21]. Carbon nanotubes are characterized by physicochemical properties, such as stronger adsorption capacity and more powerful adsorption capability than primary secondary amine (PSA) and octadecylsilane chemically bonded silica gel $\left(\mathrm{C}_{18}\right)$. Multi-walled carbon nanotubes (MWCNTs) have been widely used for the detection and quantification of pesticides at the trace levels [22-27].

The pesticides structures of fenpropathrin, cyfluthrin, cyhalothrin, fenvalerate, and deltamethrin were shown in Figure 1. This research determined fenpropathrin, cyfluthrin, cyhalothrin, fenvalerate, and deltamethrin residue in liquid milk by GC using MWCNTs as d-SPE sorbent and obtained satisfactory results through optimization of conditions, which is applicable to detection of pyrethroid pesticide residues in liquid milk.

\section{Experimental}

Chemicals and Reagents. MWCNTs (length, 0.5-2.0 $\mu \mathrm{m}$; external diameter, $8-15 \mathrm{~nm}$ ) were purchased from Beijing DeKe Daojin Science and Technology Co., Ltd., China. PSA was obtained from CNW Technologies (CNW, Germany). $\mathrm{C}_{18}$ was obtained from Dikma Technologies (Beijing, China). Fenpropathrin, cyhalothrin, cyfluthrin, fenvalerate, and deltamethrin of $98 \%$ purity were purchased from the AgroEnvironmental Protection Institute, Ministry of Agriculture (Tianjin, China). Methanol and acetonitrile (HPLC grade) were purchased from Fisher Scientific (Fair Lawn, NJ, USA). Sodium chloride was calcined at $650{ }^{\circ} \mathrm{C}$ for $4 \mathrm{~h}$ before it can be used. Liquid milk was purchased from Dongan Market (Daqing, China). Watsons water (Watson Group Hong Kong

This is an open-access article distributed under the terms of the Creative Commons Attribution-NonCommercial 4.0 International License (https://creativecommons.org/licenses/by-nc/4.0/), which permits unrestricted use, distribution, and reproduction in any medium for non-commercial purposes, provided the original author and source are credited, a link to the CC License is provided, and changes - if any - are indicated. 
<smiles>C=CC1C(C(=C)OC(C#N)(c2ccc(F)c(Oc3ccccc3)c2)C2C(C=C(Cl)Cl)C2(C)C)C1C(=O)OC(C#N)c1cccc(Oc2ccccc2)c1</smiles>

(A)<smiles>CC1(C)[C@@H](COC(C#N)c2cccc(Oc3ccccc3)c2)[C@@H]1C=C(F)F</smiles>

(C)

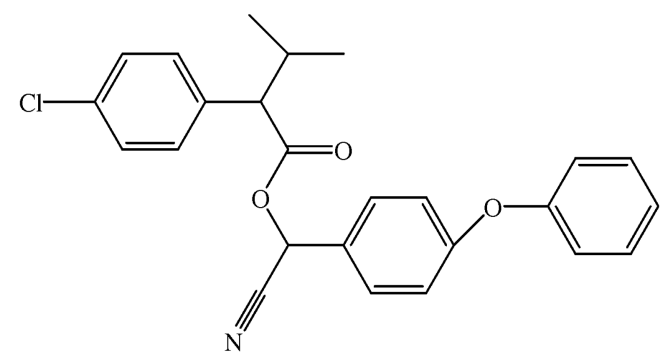

(D)

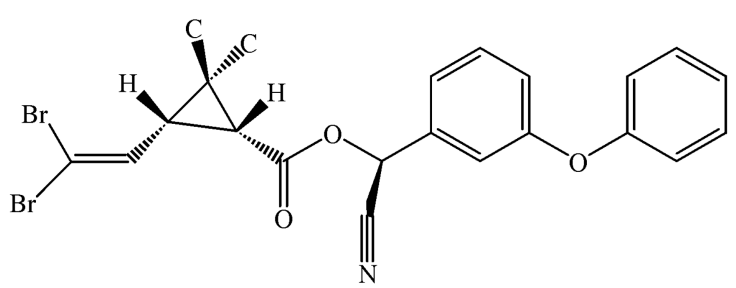

(E)

Figure 1. Structure of five pyrethroid pesticides: (A) fenpropathrin, (B) cyfluthrin, (C) cyhalothrin, (D) fenvalerate, and (E) deltamethrin

Ltd., China) was used for the measurements. All the other reagents used were at least of analytical reagent grade. The $0.22 \mu \mathrm{m}$ microporous membrane was obtained from Dikma Technologies (Beijing, China).

Instrumentation. Chromatographic analysis was performed on Agilent 7890B system (Agilent Co., USA) equipped with electron capture detector (ECD); the system was controlled by MassHunter 6.0 (Agilent Co., USA). Z $36 \mathrm{HK}$ centrifuge (HERMLE Co., Germany) was used for analysis. IKA T25 Homogenate machine (Eika Equipment Co., Germany) was used for sample treatment; Vortex-2 agitator (Si Digital Co., USA) was used for vortex; and SK8200H ultrasonic cleaners were used for sample preparation (Shanghai KUDOS Ultrasonic Instrument Co., Ltd., China). ML204 electronic analytical balance was used for analysis (Mettler Toledo, USA).

GC Condition. The separation was carried out on a DB-5 capillary column $(30 \mathrm{~m} \times 250 \mu \mathrm{m}$ i.d.; film thickness, $0.25 \mu \mathrm{m})$. Nitrogen $(99.999 \%)$ was used as the carrier gas at a flow rate of $1.0 \mathrm{~mL} \mathrm{~min}{ }^{-1}$. The oven temperature was programmed as follows: initial temperature of $150{ }^{\circ} \mathrm{C}$ (held for $1 \mathrm{~min}$ ), then to $270{ }^{\circ} \mathrm{C}$ at a rate of $10{ }^{\circ} \mathrm{C} \mathrm{min}^{-1}$, and held for $20 \mathrm{~min}$. The injector temperature was maintained at $200{ }^{\circ} \mathrm{C}$; injection mode was splitless injecting samples; and the quantity of sampling was 10 microliter.

Sample Preparation. Five milliliters of the liquid milk was placed into $15 \mathrm{~mL}$ Teflon centrifuge tube, respectively. One gram of sodium chloride and $3 \mathrm{~mL}$ acetonitrile were added to the tube (pH was adjusted between 4 and 5 by $0.1 \mathrm{~mol} \mathrm{~L}^{-1}$ of phosphoric acid) and then placed into sonic oscillator for $10 \mathrm{~min}$, followed by centrifugation for $5 \mathrm{~min}$ at $10,000 \mathrm{rpm}$. Then, $2 \mathrm{~mL}$ of the resulting supernatant was further transferred into $5 \mathrm{~mL}$ Teflon centrifuge tube, containing $50 \mathrm{mg}$ MWCNTs and $100 \mathrm{mg}$ anhydrous magnesium sulfate; the solution was vortex mixed for $1 \mathrm{~min}$ and centrifuged at 10,000 rpm for $5 \mathrm{~min}$. Finally, $200 \mu \mathrm{L}$ of the extract was transferred into sample bottle which was injected for GC analysis.

\section{Results and Discussion}

d-SPE Conditions. Liquid milk contains large amounts of protein and amino acid. A commonly used way to remove protein and fat is addition of organic solvents under acid condition to denature protein and fat. As a result, this experiment chose to add phosphoric acid, $\mathrm{NaCl}$ precipitated protein and fat under acid condition. With addition of $\mathrm{NaCl}$ to liquid milk, protein molecules cluster and settle. When $\mathrm{pH}$ is lower than protein isoelectric point, protein also clusters and settles. For the experiment, $1 \mathrm{~g} \mathrm{NaCl}$ and $3 \mathrm{~mL}$ acetonitrile were added to a sample of $5 \mathrm{~mL}$ liquid milk, and $\mathrm{pH}$ value was adjusted at 4-5 with $0.1 \mathrm{~mol} \mathrm{~L}^{-1}$ phosphoric acid solution, which produced the best result of removing protein and fat.

Effect of type extraction solvent on the recoveries of five pyrethroid pesticides, such as acetone, methanol, and acetonitrile, was researched (see Figure 2). This method works best when five pyrethroid pesticides were used as the extraction solvent with acetonitrile in liquid milk and the recoveries that reached the highest were added to $3 \mathrm{~mL}$ acetonitrile with $5 \mathrm{~mL}$ in liquid milk sample. As the extraction was chosen by acetonitrile with $3 \mathrm{~mL}$ (see Figure 3).

Sorbent of PSA and $\mathrm{C}_{18}$ was used to d-SPE on sample pretreatment. PSA can effectively remove components such as fatty acid, sugar, and phenol in acetonitrile extract, and $\mathrm{C}_{18}$ is a 


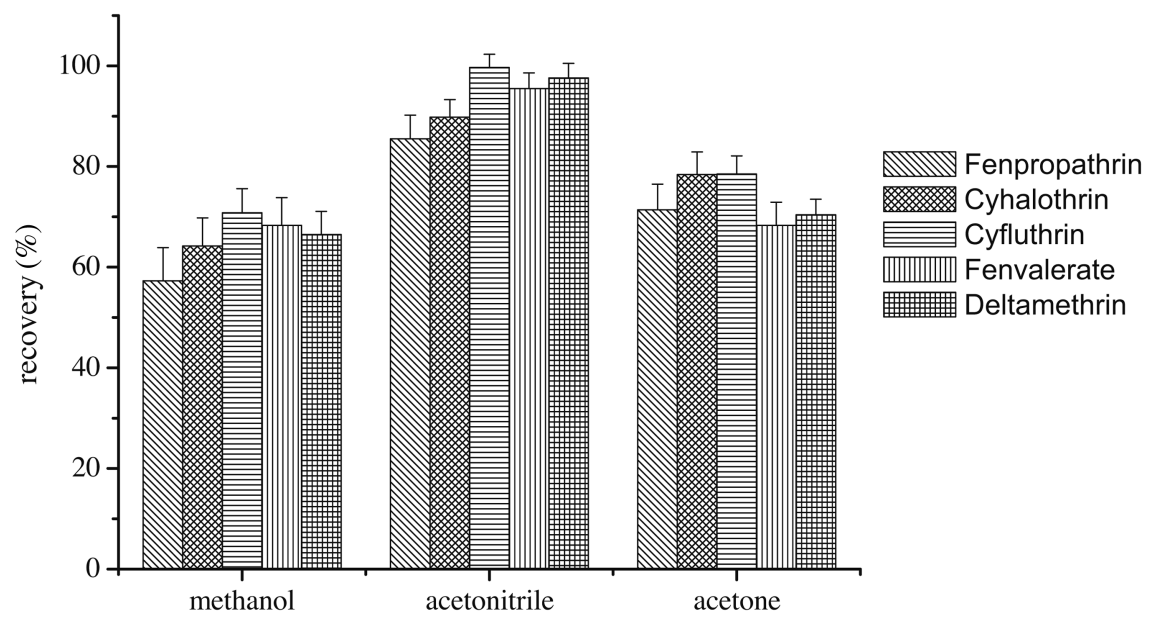

Figure 2. Effect of extraction solvent on the recoveries of five pyrethroid pesticides

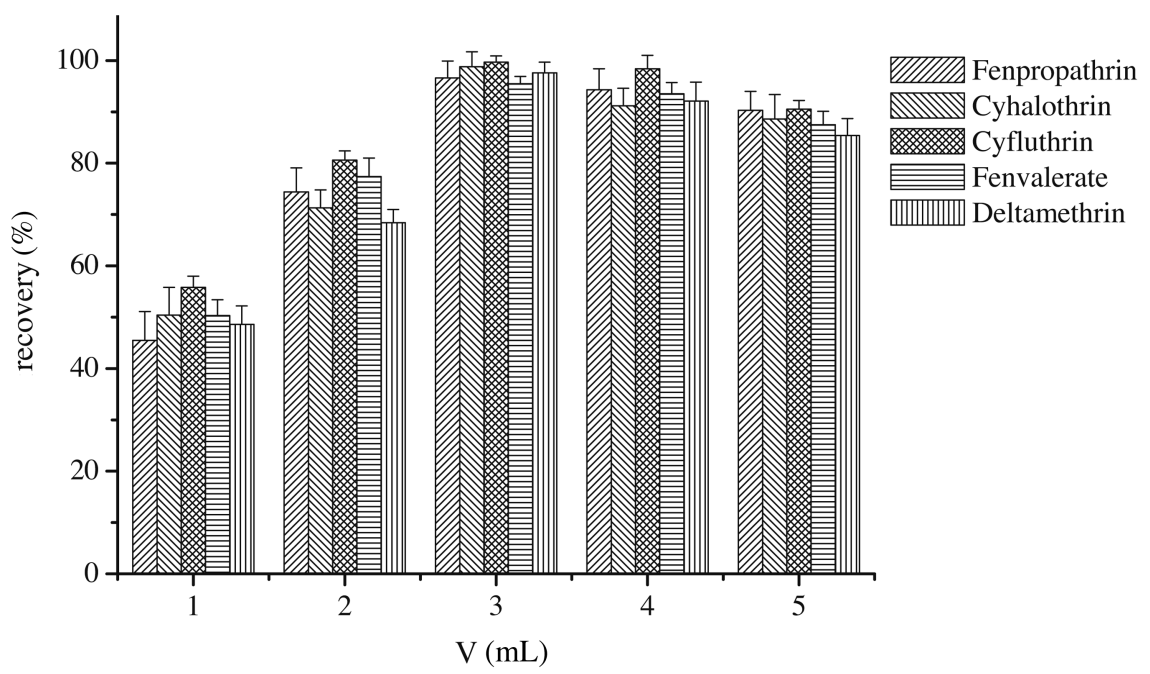

Figure 3. Effect of sorbent volume on the recoveries of five pyrethroid pesticides

good remover of fat. In our study, sorbent of MWCNTs, $\mathrm{C}_{18}$, and PSA was compared with purification effect on the recoveries of five pyrethroid pesticides. It was found that both PSA and MWCNTs could effectively remove impurities with high recoveries in liquid milk, the purification effect of $\mathrm{C}_{18}$ was not as good as MWCNTs, there were numerous impurity peaks in a sample with the use of $\mathrm{C}_{18}$ and octadecylsilane chemically bonded silica gel forming hydrogen bond with five pyrethroid pesticides, and the recoveries of the target compound were decreasing. The price of PSA was much higher than that of MWCNTs (see Figure 4). Therefore, MWCNTs were used in sample preparation to obtain satisfactory recoveries of five pyrethroid pesticides.

The different dosages of MWCNTs $(25 \mathrm{mg}, 50 \mathrm{mg}, 75 \mathrm{mg}$, and $100 \mathrm{mg}$ ) were evaluated, and the effect on the recoveries of five pyrethroid pesticides was identified. The results show that

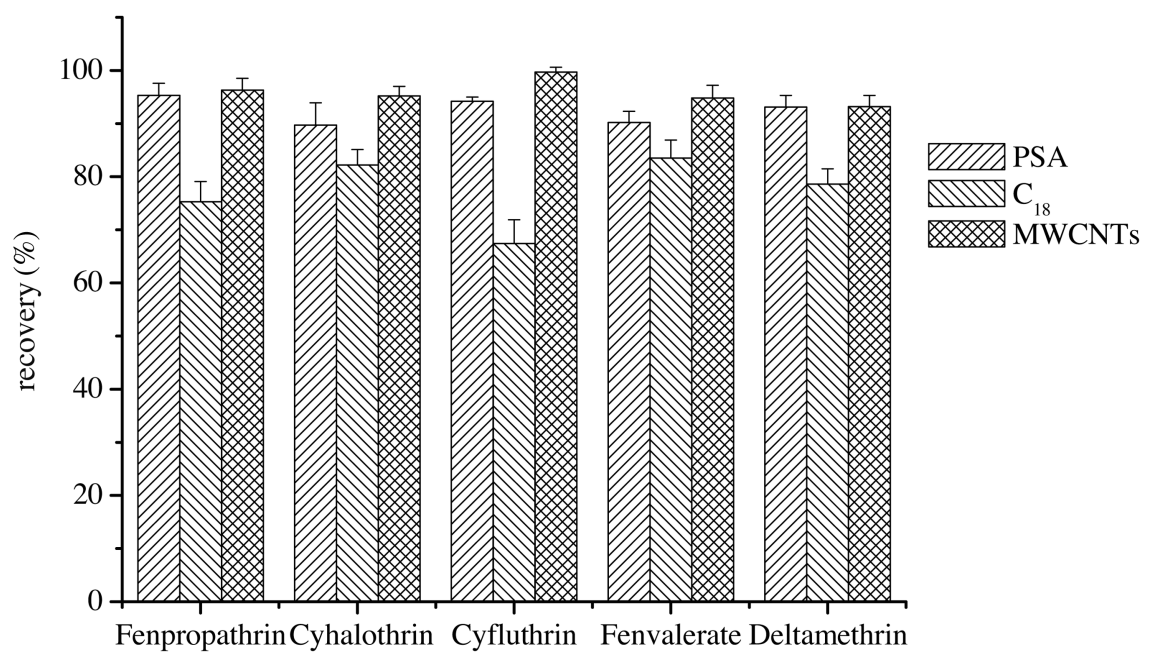

Figure 4. Effect of type of sorbent on the recoveries of five pyrethroid pesticides 


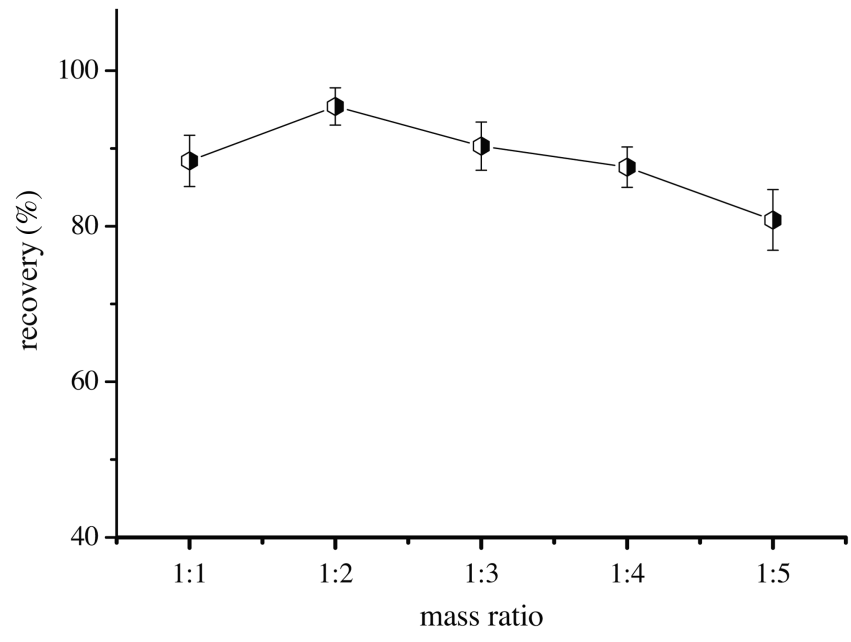

Figure 5. Effect of MWCNTs and magnesium sulfate anhydro mass ratio on the recoveries of five pyrethroid pesticides

the recoveries of five pyrethroid pesticides were raised with the increasing of MWCNTs; when the dose of MWCNTs was 50 $\mathrm{mg}$, the recoveries had declined with the dosage of MWCNTs increasing. Therefore, $50 \mathrm{mg}$ of MWCNTs was added into the sample, applying purification satisfactory recoveries for liquid milk. As can be seen in Figure 5, mass ratio of MWCNTs to anhydrous magnesium sulfate was $1: 2$, and satisfactory recoveries were obtained; rate decreased slightly, which is, when the content of MWCNTs was $50 \mathrm{mg}$, satisfactory recoveries of five pyrethroid pesticides were between $81.8 \%$ and $112.6 \%$; the purification effect and experimental cost were considered on sample preparation; and the amount of MWCNTs $50 \mathrm{mg}$ was selected.

Matrix Effect. The occurrence of matrix effect (ME) is mainly from the endogenous component of the samples. Matrix effect has significant interference for the analysis of the targets and affects the accuracy and precision of the method. Therefore, it is necessary to investigate the matrix effect.

ME was established in liquid milk. To investigate the ME, a series of responds was set as follows. A was standard solution in hexane, B was set as the responds of real samples, and $\mathrm{C}$ was matrix-matched standard. Then, the ME was calculated from the following equation. $\mathrm{ME}$, their precision (relative standard deviation [RSD], $n=6$ ) of the proposed method in liquid milk spiked at the three level was indicated in Table 1.

$$
\operatorname{ME}(\%)=(\mathrm{C}-\mathrm{B}) / \mathrm{A} \times 100
$$

Under the premise that the chromatographic condition is good, the method to eliminate or reduce the matrix effect is the appropriate sample pretreatment. The results show that ME of liquid milk has a strong furtherance effect on pyrethroid pesticides. The possible reason is that there would be an obvious decreasing in the endogenous component of the liquid milk samples to increase the influence of coexisting matrix constituents. In order to make certain the universality and applicability with the established method, in this study, liquid milk matrix preparation standard solution was used to eliminate matrix effect.

Method Validation. Matrix of liquid milk free of pesticide, spiked at set concentration levels $\left(20 \mu \mathrm{g} \mathrm{kg}^{-1}, 50 \mu \mathrm{g} \mathrm{kg}^{-1}, 100 \mu \mathrm{g}\right.$ $\mathrm{kg}^{-1}, 250 \mu \mathrm{g} \mathrm{kg}^{-1}$, and $500 \mu \mathrm{g} \mathrm{kg}^{-1}$ ) of five pyrethroid pesticides, was used to prepare a series of matrix-matched calibration curves. According to peak area (A) and concentration of spiked sample (C, $\left.\mu \mathrm{g} \mathrm{kg}^{-1}\right)$ drawing standard curve, the linear relation between peak area and concentration of the five pyrethroid pesticides was good in the range of 20 to $500 \mu \mathrm{g} \mathrm{kg}^{-1}$ (the linear equation, the correlation coefficient, the limits of detection (LODs), and limits of quantity (LOQs) are summarized in Table 2). LODs and LOQs were calculated based on three and ten times of standard deviations of the resulted values, respectively. As can be seen in Table 2, good linear relationships were observed between responses of GC detector and concentrations of analytes within ranges of test and LODs were low enough.

For the determination of the accuracy, recovery experiments were performed using three different concentration levels $(20 \mu \mathrm{g}$ $\mathrm{kg}^{-1}, 50 \mu \mathrm{g} \mathrm{kg}^{-1}$, and $100 \mu \mathrm{g} \mathrm{kg}^{-1}$ ) of real samples spiked with known amounts of five pyrethroid pesticides standard, respectively. The samples were measured using the optimized procedures established above, intra-day with 6 injections per level, and inter-day with 3 injections per level, which were tested for matrix standard. The recoveries and RSDs are summarized in Table 3. The recoveries were in the range of $81.8-112.1 \%$, and RSDs were in the range of $1.9-5.7 \%$.

Analysis of Real Samples. To evaluate the performance of the presented method and use condition of five pyrethroid pesticides in liquid milk, the proposed analytical procedure was applied to the analysis of real samples and spiked sample. Liquid milk was purchased from Dong'an Market; the samples were pretreated according to section sample preparation, which were then determined by GC according to GC conditions. The results show that five pyrethroid pesticides were not detected in liquid milk, as shown in Figure 6. Recoveries of quality control sample were satisfied with analysis of the requirements, indicating that the results were accurate and reliable.

\section{Conclusion}

In this study, d-SPE has been developed as a novel method for determination of five pyrethroid pesticides with $50 \mathrm{mg}$ MWCNTs as adsorbent combined with gas chromatography coupled with ECD in liquid milk. After a careful optimization and reaching below LODs and LODs at the $4.86 \mu \mathrm{g} \mathrm{kg}^{-1}$

Table 1. Matrix effect of five pyrethroid pesticides in liquid milk

\begin{tabular}{|c|c|c|c|c|c|}
\hline Pesticides & Response value of the standard solution in hexane & Response value of matrix-matched standard & Real sample & ME (\%) & RSD (\%) \\
\hline Fenpropathrin & 139.8215 & 161.5111 & ND & 115.5 & 4.1 \\
\hline Cyhalothrin & 239.1718 & 247.7614 & ND & 103.6 & 3.9 \\
\hline Cyfluthrin & 138.2221 & 156.3886 & ND & 113.1 & 3.2 \\
\hline Fenvalerate & 97.6788 & 132.6874 & ND & 135.8 & 5.2 \\
\hline Deltamethrin & 130.2613 & 128.2907 & ND & 98.5 & 4.5 \\
\hline $\mathrm{ND}$, not de & ted. & & & & \\
\hline
\end{tabular}

Table 2. Calibration parameters of analytes

\begin{tabular}{llccrrr}
\hline Pesticides & \multicolumn{1}{c}{ Linear equation } & Correlation coefficient, $r$ & Linear range $\left(\mu \mathrm{g} \mathrm{kg}^{-1}\right)$ & $\mathrm{LOD}\left(\mu \mathrm{g} \mathrm{kg}^{-1}\right)$ & $\left.\left.\mathrm{LOQ}_{(\mu \mathrm{g} \mathrm{kg}}\right)^{-1}\right)$ & $\mathrm{RSD} / \%$ \\
\hline Fenpropathrin & $\mathrm{A}=33,451 C-172.568$ & 0.9985 & $20-500$ & 2.62 & 8.73 & 4.7 \\
Cyhalothrin & $\mathrm{A}=54,183 C+99.434$ & 0.9990 & $20-500$ & 3.34 & 11.1 \\
Cyfluthrin & $\mathrm{A}=53,627 C-186.869$ & 0.9978 & $20-500$ & 4.86 & 1.2 \\
Fenvalerate & $\mathrm{A}=45,534 C-108.562$ & 0.9987 & $20-500$ & 3.57 & 16.2 \\
Deltamethrin & $\mathrm{A}=35,071 C-162.538$ & 0.9983 & $20-500$ & 4.75 & 1.9 & 3.4 \\
\hline
\end{tabular}


Table 3. The result of the experiment recoveries and RSDs of the five pyrethroid pesticides

\begin{tabular}{|c|c|c|c|c|c|c|c|c|c|}
\hline \multirow[t]{2}{*}{ Pesticides } & \multicolumn{3}{|c|}{ Spiked level $\left(20 \mu \mathrm{g} \mathrm{kg}^{-1}\right)$} & \multicolumn{3}{|c|}{ Spiked level $\left(50 \mu \mathrm{g} \mathrm{kg}^{-1}\right)$} & \multicolumn{3}{|c|}{ Spiked level $\left(100 \mu \mathrm{g} \mathrm{kg}^{-1}\right)$} \\
\hline & $\begin{array}{l}\text { Average } \\
\text { recovery }\end{array}$ & $\begin{array}{c}\text { Intra-day } \\
\text { RSD }\end{array}$ & $\begin{array}{c}\text { Inter-day } \\
\text { RSD }\end{array}$ & $\begin{array}{l}\text { Average } \\
\text { recovery }\end{array}$ & $\begin{array}{c}\text { Intra-day } \\
\text { RSD }\end{array}$ & $\begin{array}{c}\text { Inter-day } \\
\text { RSD }\end{array}$ & $\begin{array}{l}\text { Average } \\
\text { recovery }\end{array}$ & $\begin{array}{c}\text { Intra-day } \\
\text { RSD }\end{array}$ & $\begin{array}{c}\text { Inter-day } \\
\text { RSD }\end{array}$ \\
\hline Fenpropathrin & 89.8 & 2.8 & 4.8 & 95.6 & 3.1 & 4.2 & 96.6 & 2.1 & 3.8 \\
\hline Cyhalothrin & 83.2 & 2.1 & 3.9 & 89.3 & 2.5 & 2.1 & 98.8 & 2.7 & 4.6 \\
\hline Cyfluthrin & 90.5 & 1.9 & 3.7 & 112.1 & 2.7 & 3.4 & 102.7 & 1.9 & 2.9 \\
\hline Fenvalerate & 82.4 & 3.4 & 5.7 & 91.4 & 2.6 & 5.7 & 95.5 & 3.1 & 4.1 \\
\hline Deltamethrin & 81.8 & 3.0 & 3.7 & 92.7 & 2.3 & 4.8 & 97.6 & 2.8 & 4.7 \\
\hline
\end{tabular}
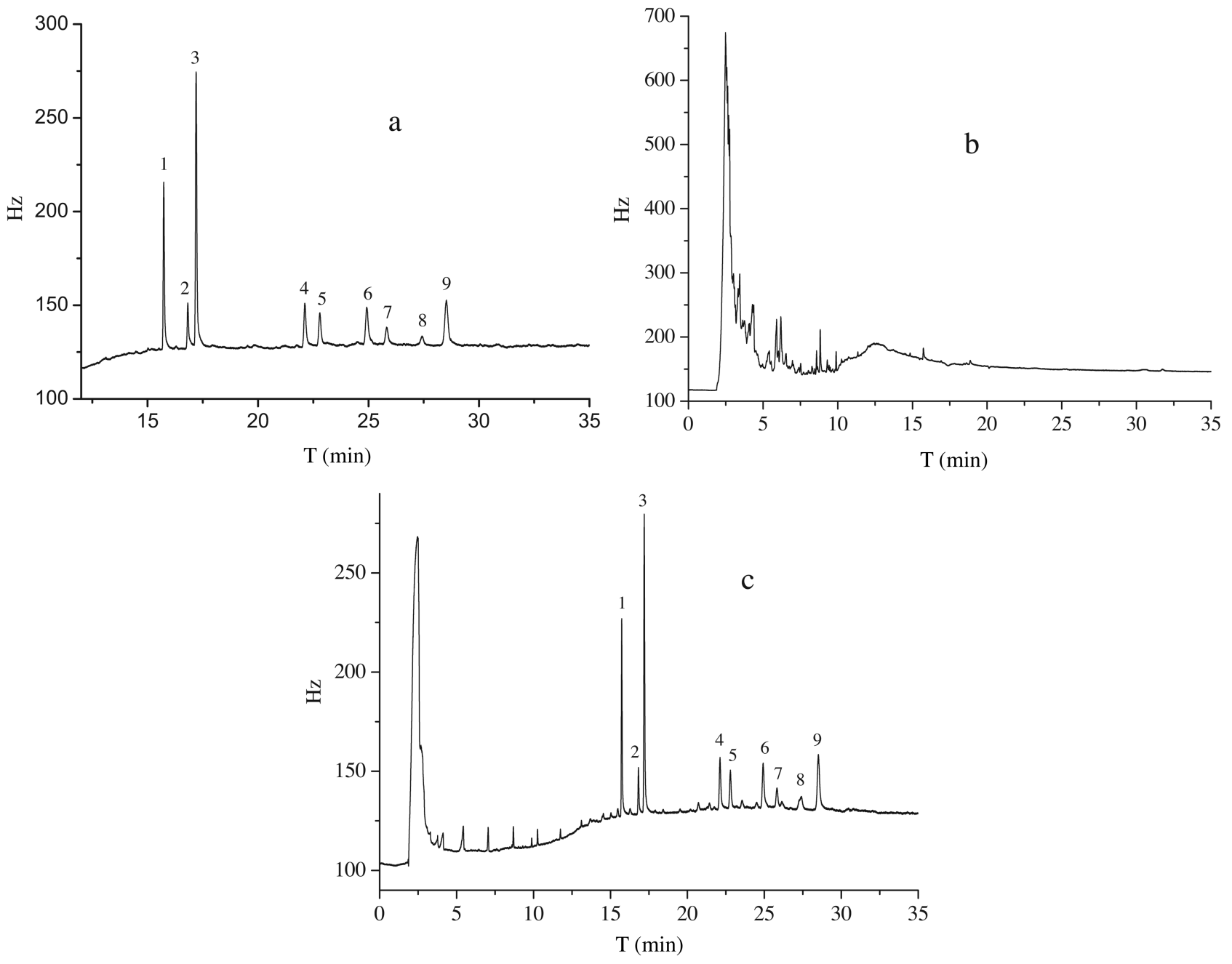

Figure 6. Chromatograms of (a) standard solution in hexane; (b) a blank sample; and (c) a mixed standard solution of liquid milk matrix (1, fenpropathrin; 2 and 3, cyhalothrin; 4 and 5, cyfluthrin; 6 and 7, fenvalerate; 8 and 9, deltamethrin)

and $16.2 \mu \mathrm{g} \mathrm{kg}^{-1}$, respectively, the analysis on the actual data shows that the method can satisfy the quick detection of five pyrethroid pesticides in liquid milk and conform to CAC, EU, and Positive List System of Japan of MRLs. The whole method has been successfully applied to five pyrethroid pesticides in liquid milk samples with satisfactory results. The method showed numerous advantages including high sensitivity, low limits of quantification, high recovery for pyrethroid pesticides, and broad application in complex sample preparation.

Acknowledgments. This work was supported by Scientific Planning Guide the Project of Mudanjiang (Project No. Z2016n0017).

\section{References}

1. Amweg, E. L.; Weston, D. P.; Ureda, N. M. Environ. Toxicol. Chem. $\mathbf{2 0 0 5}, 24,966$.
2. Farajzadeh, M. A.; Khoshmaram, L. A.; Akbar, A. N. J. Food Compos. Anal. 2014, 34, 128 .

3. Han, L. J.; Yelena, S.; Steven, J. L. Food Control 2016, 66, 270.

4. Sun, P.; Gao, Y. L.; Wang, J. M.; Liu, X. J. Chin. J. Pestic. Sci. 2016, 18, 497.

5. Irene, D.; Roberto, R. G.; Javier, A. L.; Vidal, J. L. M.; Frenich, A. G. Anal. Chem. 2016, 12, 1

6. Vázquez, P. P.; Hakme, E.; Uclés, S.; Cutillas, V.; Galera, M. M.; Mughari, A. R.; FernándezAlba, A. R. J. Chromatogr. A 2016, 1463, 20.

7. Shamsipur, M.; Yazdanfar, N.; Ghambarian, M. Food Chem. 2016, 204

8. Amelin, V. G.; Bol'shakov, D. S.; Tretiakov, A. V. J. Anal. Chem. 2012, 67, 354 .

9. Bagheri, H.; Yamini, Y.; Safari, M.; Asiabi, H.; Karimi, M.; Heydari, A. J. Supercrit. Fluids 2016, 107, 571 .

10. Bernardi, G.; Kemmerich, M.; Ribeiro, L. C.; Adaime, M. B.; Zanella, R. Talanta 2016, 161, 40

11. Fu, Y.; Yang, T.; Zhao, J.; Zhang, L.; Chen, R.; Wu, Y. Food Chem., 2017, 218, 192.

12. Tette, P. A. S.; Silvaoliveira, F. A. D.; Pereira, E. N. C.; Silva, G.; Abreugloria, M. B. D.; Fernandes, C. Food Chem. 2016, 211, 130.

13. Commission Regulation (EC) No. 178/2006 of 1 February 2006 amending Regulation (EC) No. 396/2005 of the European Parliament and of the feed products to which maximum levels for pesticide residues apply, European Union Brussels, 2006. 
14. Commission Regulation (EC) No. $149 / 2008$ of 29 January 2008 amending Regulation (EC) No. 396/2005 of the European Parliament and of thecouncil by estabishing Annexes setting maximum residue levels for products covered by Annex I, European Union Brussels, 2008.

15. Maria, F. A.; Maria, L.; Pablo Lamas, J.; Lores, M.; Garcia Jares, C.; Cela, R.; Dagnac, T. J. Chromatogr. A 2009, 1216, 2832.

16. Yang, X.; Zhang, P.; Li, X.; Hu, L.; Gao, H.; Zhang, S.; Zhou, W.; Lu, R. Talanta 2016, 153, 353.

17. Li, J.; Liu, H.; Yu, M.; Wu, L.; Wang, Q.; Lv, H.; Ma, B.; Song, Y. Anal. Methods 2014, 6, 9124.

18. Xiong, W.; Cheng, C.; Yang, Y. Anal. Methods 2015, 7, 2093.

19. Liu, Y.; Ma, Y.; Guo, L.; Yan, A.; Mao, X.; Wan, Y. Anal. Methods $\mathbf{2 0 1 5}, 7,3685$.
20. Nabil, A. A. A.; Nouri, N.; Farajzadeh, M. A. Biomed. Chromatogr. 2015, 29, 1094.

21. Aladaghlo, Z.; Fakhariand, A.; Behbahani, M. J. Sep. Sci. 2016, 1

22. Liu, X.; Zhang, H.; Li, J.; Shen, J.; Xiao, C.; Zhao, F. Food Sci. 2016, 37,216

23. Amelin, V. G.; Bol'shakov, D.S.; Tret'yakov, A. V. J. Anal. Chem 2013, 68, 386.

24. Zhao, H.; Jia, Y.; Ding, M.; Zhao M. Chin. J. Chromatogr. 2011, 29, 443

25. Rong, J.; Wei, H.; Huang, H.; Wu, H.; Xu, M.; Li, Y. J. Instrum. Anal. 2016, 35,8 .

26. Amelin, V. G.; Lavrukhin, D. K. J. Anal. Chem. 2016, 71, 359

27. Cao, H.; Chen, X.; Zhu, Y.; Li, Z. Chem. Res. Chin. Univ. 2013, 34, 2710. 